\title{
O COMUNISMO NAS LETRAS BRASILEIRAS: A DÉCADA DE 1930
}

\author{
Denise Adélia Vieira
}

Teresinha $V$. Zimbrão da Silva

REsumo: Este trabalho conta a história das relações entre os intelectuais brasileiros e o Comunismo na década de I930, mostrando a filiação dos escritores ao partido comunista e sua adesão à literatura proletária.

Palavras-chave: Literatura; Comunismo; Intelectuais

\section{OS INTELECTUAIS E O COMUNISMO}

Procurei aqui em São Paulo alguns livros de Marx, como O Capital, e não pude encontrar. Ninguém nas livrarias sabia o que era isso. O Brasil, nesse sentido, estava longe do resto do mundo. Importei os livros da Europa e comecei a ler.

(Prado Júnior apud Konder, I99I)

No final da década de 20, no Brasil, ocorre a tomada de consciência ideológica de intelectuais e artistas, então seduzidos pela política e pelo РСв. O crescimento da imprensa comunista, atuante desde I922, contribui para

I Pós-graduada pela ufJF (MG).

2 Professora da UfJF (MG). 
essa conversão. Publicações fazem-se notar, tal como a da revista Movimento Comunista, que surge como um eficiente meio de propaganda e difusão do comunismo. A edição de livros no Brasil é noticiada pela revista e sinaliza o esforço de alterar o quadro da quase inexistência de literatura comunista entre nós. Mesmo após a Revolução de 30, a situação não muda muito no que se refere aos livros de Marx. Mas se sabe que Os princípios do comunismo, de Engels, e o $A B C$ do comunismo, de Bukharin, são dois livros que têm grande influência nesses anos.

A década de 30, portanto, apesar de se iniciar sob o signo de forte repressão aо РСв, vai aos poucos desenvolvendo um clima cultural propício à divulgação de livros comunistas e de textos sobre a União Soviética. Nessa altura, começam a ser discutidas as noções de "luta de classes", "espoliação", "mais-valia", "moral burguesa" e "proletariado".

O comunismo se faz notar nos textos de vários ensaístas, sociólogos e, especialmente, de ficcionistas, que se deixam contagiar pelas idéias revolucionárias. Forma-se, então, um relativo público leitor e um mercado de livros e periódicos no país. Na revista Boletim de Ariel, a partir de I930, registram-se importantes debates político-culturais, como aquele centrado no socialismo soviético e o que se volta para a literatura proletária.

$\mathrm{O}$ comunismo veio a ser finalmente divulgado entre os intelectuais brasileiros, ainda que Marx permanecesse quase um desconhecido, conforme confessa Jorge Amado, em entrevista a Raillard:

"Eu nunca lera Marx, não sei se muitos dentre nós o leram, [...] mas a maioria dos líderes do PC sem dúvida jamais o leu."(Amado apud RaIllard, 1990, p. 74)

Das leituras, alguns intelectuais passaram de fato à filiação ао РСв. Se, no resto do Ocidente, esse engajamento já se estava dando desde a Revolução Russa de I9I7, no Brasil foi, sobretudo, a partir da Revolução de I930 que ocorreram efetivas adesões ao partido. A Revolução de I7 certamente 
sensibilizou os intelectuais brasileiros, contudo, o ano de 1930 foi notoriamente o marco para que o comunismo ascendesse aos debates nacionais.

As adesões de intelectuais aо Рсв acontecem no momento em que o Partido se "bolcheviza", submetendo-se mais rigidamente às ordens e regras da III Internacional Comunista.

Desde fins de 1929 até meados de 1934, о РСв empreendeu o programa de proletarização do Partido, que desembocou no obreirismo, uma versão que incitou "desprezo" pelos aliados de outras classes. Seguiu-se o afastamento dos militantes intelectuais que ocupavam postos de direção, os quais passaram a ser ocupados por militantes de origem proletária.

Esta política se caracterizou pela valorização do modo de vida proletário, em detrimento do intelectualismo burguês, apontado então como responsável pelo imobilismo do Partido. Aqueles militantes de origem intelectual que pretendessem continuar nas fileiras do Partido deveriam experimentar o modus vivendi do trabalhador e exaltar as virtudes proletárias. O programa testaria, assim, as escolhas partidárias dos intelectuais.

Ao centrar as suas propostas em torno da proletarização, о РСв pretendia uma revisão das funções assumidas pelos intelectuais até então representantes da burguesia. $\mathrm{O}$ intelectual que desejasse ingressar nо Рсв tinha de passar por vários testes para mostrar que poderia fazer parte do proletariado, provando, assim, afinidades com esta classe.

Além disso, "travestido" de operário, o intelectual poderia transmitir nos seus escritos, de modo mais "verdadeiro", as experiências adquiridas com o mundo do trabalho. Defendendo o obreirismo, Amado afirma:

Indomável partido do proletariado! E dos sábios e dos escritores! Onde iríamos nós caber, por acaso, senão dentro deste partido que é do povo? Só nas fileiras poderemos fortalecer, ao contato com o proletariado e o povo, a nossa capacidade de criação artística e cientifica. (AMADO, I946, p.II) 
Contudo, dado o peso excessivo das obrigações impostas aos militantes, foram muitos os que não acolheram o obreirismo em sua prática com o entusiasmo de Amado, ainda que acolhessem o "proletariado" como tema em seus escritos.

\section{A literatura e o “Proletariado"}

Grande parte da literatura que se desenvolveu na década de 30 no Brasil preocupou-se em trazer para as letras brasileiras o tema pouco explorado do cotidiano do trabalhador oprimido, incluindo o proletário, que emergia então no cenário nacional como fruto da miséria urbano-industrial.

Nessa nova interpretação da realidade do trabalho no Brasil, os escritores tentaram assumir, em seus textos, o discurso da classe trabalhadora, problematizando a idéia de que o intelectual não seria capaz de interpretar, de fato, os interesses dos oprimidos. Essa problemática aparece explícita no seguinte pronunciamento de Jorge Amado:

"Continuar, apesar de saber que nunca serei um escritor operário. Pequeno burguês, com os vícios de origem, não possuo a grande poesia, a grande pureza, a força, que hoje, no mundo, só tem o proletariado revolucionário." (AмAdo apud TAтI, I96I, p. 59).

O mesmo Amado, ao se desculpar por ser um "pequeno burguês", não deixa, por outro lado, de acreditar na "verdade" da sua literatura:

"É evidente [...] que os nossos livros, volumes de pequenos burgueses que aderiram ao proletariado, podem ser ingênuos e falhos. Apesar de tudo, eles falam uma linguagem nova e verdadeira (AMADo apud TATI, I96I, p. 59). 
Essa linguagem "nova e verdadeira" teria sido adquirida no contato com o mundo proletário. Submetendo-se ao obreirismo por exigência do PCB, o escritor militante conseguiria para os seus livros a contribuição de dados, que observaria in loco. Discutiria, com a "força de documentos", a exploração a que o trabalhador era submetido: parcos salários, condições precárias, carência de moradias, moléstias - em suma, extrema miséria.

\section{Os FILIADOS}

O verdadeiro intelectual é aquele que, além de se engajar politicamente, opta pelo comunismo.

(Jorge Amado,I993)

Dentre os escritores que se filiaram ao РСв na década de 30, selecionamos alguns para comentar em seguida. Suas posições em relação ao obreirismo e à literatura proletária constituem, ao nosso ver, uma síntese de aspectos importantes do engajamento do intelectual brasileiro do período. Engajamento que teve seu ponto máximo com a Intentona Comunista de 1935, cujo fracasso reforçou o autoritarismo do presidente Getúlio Vargas e intensificou a perseguição aos comunistas.

\subsection{Raguel De Queiroz e o comunismo}

[...] lia principalmente os russos, Dostoierski, Gorki, Tolstoi, e todos aqueles dos quais mamãe me passou a sua paixão. Epor isso, Socialismo, Revolução Russa, Comunismo e, até mesmo, Marxismo propriamente dito, já me eram, então, assuntos familiares

(Raquel de Queiroz, I998) 
Raquel de Queiroz exerceu uma militância política precoce. Já publicara O Quinze, seu primeiro romance, quando se filiou ao Partido Comunista, em I93I, aos 20 anos.

No livro de memórias, Tantos Anos (1998), de Raquel e Maria Luíza de Queiroz, Raquel recorda sua militância política nо Рсв. Seu ingresso se deu em um momento de grande seletividade partidária e de repressão governista:

Quando nele entrei, o Partido mal completara dez anos de vida no Brasil. E já havia uma rede de comunistas pelo país inteiro: onde a gente chegava, encontrava amigos. Os mais ruidosos eram os simpatizantes, os que tinham compromisso ideológico firmado. Aliás, nessa época, entrar para o Partido não era fácil. Os simpatizantes ficavam muito tempo em periodo de provação. Era mister dar provas durante anos, principalmente no que se referia à submissão ideológica ao stalinismo. Pois essa foi a fase mais temivel do stalinismo, logo depois da morte de Lenine. Quando me tornei trotskista, Trotsky já fora, havia três anos, expulso da Rússia. E o PC brasileiro de então já estava bem organizado. Talvez a rede não fosse imensa, mas era estendida, ocupava todo o país. E, uma vez que no sistema de I930, tempo de ilegalidade, ninguém podia ir abertamente se manifestar na rua, aproveitavam-se, então, os movimentos liberais, como, por exemplo, a revolução de São Paulo em 1932. A primeira vez em que o comunismo mostrou a cara na rua foi em I935; mas, antes disso, descoberto qualquer movimento ilegal, a repressão era implacável. (Queinoz et al., I998, pp. 73-74).

Imbuídos de um ideal, dispunham-se os militantes a aceitar todas as submissões exigidas pelo Partido, até mesmo a possibilidade de morrer, de matar, a fim de conquistar a simpatia da cúpula dirigente. A mocidade mais intelectualizada era dominada por uma vontade, quase uma obrigação, de pertencer a algum movimento político. O ídolo dos militantes era Luís Carlos Prestes, o principal elemento de contato com a União Soviética: "Tudo o que se recebia de lá vinha através do Uruguai e era 
então passado para o pessoal do Rio, que distribuía o material para nós, nos estados. E tudo mal traduzido do espanhol" (Queiroz; Queiroz, I998, p. 37).

Em I93I, Raquel já estava, como muitos, "politizada" e "comunizada". A inserção nо РСв se dava na mais absoluta clandestinidade, por conta da repressão:

[...] Não me lembro de fazerem inscrições em livro ou mesmo em papel apropriado; nem boletins, nem ordens de serviço, nada. Ao contrário, era preciso ter mais cuidado com papéis, documentos e até livros, porque a polícia era brutal e levava logo tudo para a cadeia. Papéis e pessoas (QueIroz et al., I998, p. 37).

Nesse ano, regressou ao Ceará e levou consigo credenciais do Partido e a missão de promover a reorganização do Bloco Operário e Camponês, esmagado pela polícia presidencial. Devido às dificuldades encontradas para organizar um grupo coeso pois, em Fortaleza, havia um reduzido número de militantes instruídos, Raquel tornou-se uma espécie de consultora, logo, promovida ao cargo de secretária do РСв no Ceará - não por mérito, diz ela, mas por ser capaz de escrever e datilografar. Recebia as correspondências e o material de propaganda e participava assiduamente das reuniões clandestinas, sendo que várias delas foram realizadas no Pici (sítio da família da escritora), que era um ponto, até então, fora de qualquer suspeita. Em 1932, em visita ao Rio, foi encarregada de estabelecer contatos, receber palavras de ordem e material de propaganda:

A célula a que me dirigiram costumava reunir-se no coreto da praça da estação do Méier. Ia-se de trem até lá. Três a quatro pessoas, homens e mulheres, às vezes fingindo-se de namorados. [...] Eu andava metida em cheio não só com o Partido, mas com uma porção de gente que estava na ilegalidade. Esse curto periodo de 1932 foi a minha mais prolongada fase de militante. 
Pouco depois rebentou a revolução de 1932 em São Paulo e nós resolvemos apoiá-la, embora fosse uma revolução de caráter burguês. Era, porém, um levante contra a ditadura de Getúlio, já então nosso inimigo. (QueIroz et al., I998, p. 38).

O rompimento de Raquel com о Рсв coincidiu com a política de proletarização e com a desconfiança em relação aos intelectuais militantes. Ao chegar ao Rio, em 1932, trouxe consigo os originais de seu segundo romance, João Miguel. O romance tem como espaço o Ceará e revela, com intensidade, a problemática social do Nordeste: a miséria, a seca, a desigualdade, a indiferença dos poderosos diante de tão grave situação. Assim que souberam do romance, os dirigentes do Partido exigiram que ela entregasse os originais para uma avaliação: só então, após a leitura, feita por uma comissão, designada pelo Partido, permitiriam - ou não - a publicação. Mesmo contrariada, foi condescendente:

Obedeci, de má vontade. Mas na província de onde eu vinha fazia-se, entre os comunistas, muita questão da disciplina, no caso especial dos "intelectuais". Os operários, que compunham a aristocracia dos grupos marxistas, exigiam de nós obediência cega. Os intelectuais eram por eles considerados uma espécie de subclasse, pouco merecedora de confiança. (QueIroz et al., I998, p. 39)

Deixaram-na sem resposta durante um mês; depois disso, foi procurada pelo Partido a fim de receber a "decisão" sobre o romance:

[...] O presidente, declarando que acabara de chegar da União Soviética (eles jamais diziam Rússia), trazia ordens expressas de conter as infrações dos intelectuais. Afirmava ter lido atentamente o meu romance. E concluira que eu não poderia receber permissão para o publicar sem fazer importantes modificações na trama, carregada de preconceitos contra a classe operária. (QUEIROz et al., I998, p. 40-4I) 
Raquel nos conta os "preconceitos" que o presidente então sublinhou no seu romance:

[...] uma das heroinas, mosa rica, loura, filha de coronel, era uma donzela intocada. Já a outra, de classe inferior, era prostituta. Eu deveria, então, fazer da loura a prostituta e da outra a moça honesta. João Miguel, 'campesino', bêbedo, matava outro 'campesino'. O morto deveria ser João Miguel e o assassino passaria de 'campesino' a patrão. Indicou mais outras modificaçôes menores, terminando por sentenciar: "Se não fizer essas modificações básicas, não podemos permitir que a companheira publique o seu romance". (QUEIROz et al., I998, p. 40-4I)

Raquel conclui o episódio:

Ele tinha nas mãos, num rolo de papel pardo, a única cópia do livro que eu possuia, mal datilografada por mim mesma, na minha velha Corona. Levantei-me, devagar, do meu banco. Cheguei à mesa, estendi a mão e pedi os originais para que pudesse operar as modificaçôes exigidas. O homem, severo, me entregou o rolo. Eu olhei para trás e vi que estava aberta a porta do galpão, a sua única saida. $E$, em vez de voltar para o banco, cheguei até o meio da sala, virei-me para a mesa e disse em voz alta e calma: "Eu não reconheço nos companheiros condições literárias para opinarem sobre a minha obra. Não vou fazer correção nenbuma. E passar bem!" Voltei-me para a porta e meti o pé na carreira. (QueIroz et al., I998, p. 40-4I)

Após este acontecimento, Raquel não teve mais contato com os dirigentes do Partido. No primeiro número de $A$ Classe Operária (órgão oficial do Partido Comunista), publicado logo após o incidente, registrou-se em letras garrafais que Raquel havia sido "irradiada” (expulsa) do Partido por ideologia fascista, trotskista e por ser inimiga do proletariado.

Em 1936, Queiroz empreenderia, com Caminho de Pedras, uma crítica severa à política de "proletarização" do Partido. O romance retrata as lutas 
internas entre os comunistas de Fortaleza dos anos 30. A autora procura mostrar a falta de coesão do grupo que se dividia entre os "de gravata", representado pelos intelectuais e os "de tamancos", formados pelos operários. Ela insiste, no romance, em afirmar que a proletarização dos intelectuais não foi marcada por uma real conversão. Estes conheciam somente uma pequena parte dos problemas vividos pelos trabalhadores; dificilmente poderiam vivenciar de forma legítima a vida proletária. $\mathrm{O}$ obreirismo gerou rixas entre os operários e intelectuais, fato registrado em Caminho de Pedras:

[...] os intelectuais surgiam em bando, eram ruidosos e alegres como estudantes.

[...] Repetiam a toda hora "camaradas", afetavam uma simplicidade excessiva, que chocava os outros, os "de tamanco", cheios de preconceito e convençôes. Pois a simplicidade, longe de ser um atributo dos humildes, é um artifício de requintados que a plebe desconhece. Depressa, essa diferença cavou divergências. Os "tamancos" entraram a hostilizar os "gravatas", a "desmascará-los", a exigir que se "proletarizassem". (QueIroz, I976, p. 37)

Caminho de Pedras ilustra ainda as rivalidades pela disputa da direção da organização, idênticas àquelas travadas internamente nо РСв:

E a luta pelas posições dentro da organização armou-se aberta. Declaravam os operários que os intelectuais eram incapazes de exercer um cargo de confiança porque lhes faltava "consciência proletária". E os outros, certos da sua superioridade de intelectuais, disputavam abertamente as posições, faziam ressaltar perversamente as falhas e erros dos "eleitos". (QUEIrOz, I976, p. 37)

Com a chegada do Estado Novo, em I937, a escritora acabou sendo presa, no Ceará, por força de suas convicções trotskistas. Exemplares de seus livros, junto aos de Jorge Amado e Graciliano Ramos, foram quei- 
mados em praça pública; e ela passou três meses detida no quartel do Corpo de Bombeiros de Fortaleza.

\subsection{UM ESCRitor do PARTido}

Desapareceu o homem sem partido. Hoje ele é tão raro como um animal pré-histórico. Desapareceu, por consequência, a literatura desinteressada. Os intelectuais que não estão de um lado estão de outro. Impossível existir o indiferente. Como impossivel é existir o livro sem finalidade. Mesmo porque quem não está com o proletariado está necessariamente contra ele.

(Jorge Amado, I946, p. 57)

$\mathrm{Na}$ década de 30, Jorge Amado mudou-se para o Rio e participou ativamente do debate intelectual que levaria os escritores de então ao Fascismo, ao Catolicismo ou - como foi o caso de Amado - ao Comunismo. Conheceu Raquel de Queiroz e, por influência desta, chegou à militância política, como afirma em entrevista a Raillard, realizada em 1985:

"Raquel chegou ao Rio, passamos o tempo todo juntos. Foi em grande parte sob sua infuência que eu efetivamente me engajei no movimento comunista." (Amado apud Raillard, I990, p. 49).

Dedicou-se, então, à leitura de livros como "[...] A Bagaceira, de Zé Américo, Menino de Engenho, de Zé Lins, Judeus sem Dinheiro, de Mike Gold, Passageiros de Terceira, de Kurt Klaber, A torrente de Ferro, de Serafimovitch, A Derrota, de Fadeev, A Cavalaria Vermelha, de Babel [...]. Lendo A Baga- 
ceira virei escritor brasileiro, lendo os russos, o alemão e o judeu norte-americano desejei ser romancista proletário. (AMADO, 1993, p. 183)

Jorge Amado também leu o russo Máximo Gorki. Em suas memórias Navegação de Cabotagem confessa:

"O russo é autor de minha devoção, com ele aprendi a amar os vagabundos; devorei-lhe os contos, os romances, o teatro." (АMADo, 1993, p. 248-249)

O primeiro romance de Amado, O país do Carnaval, foi publicado em 1931, antes de o escritor ingressar na política e se tornar um militante comunista. Cacau, seu segundo romance, escrito em fins de 32 e publicado em 33, já sofreu a influência do Partido. Amado tentou escrever um romance comprometido com a transformação da sociedade, numa perspectiva que atendia à política do Partido: o intelectual deveria produzir ficção com força de "documento", denunciando a existência de segmentos sofredores da população.

Sobre essa força de "documento", declararia Amado em entrevista à imprensa em 1933:

"Cacau é resultado da minha infância, passada na cidade de Ilhéus e seus poroados e nas fazendas de cacau. Há muito que eu imaginava escrevê-lo. Tinha, para isso, uma grande documentação". (AMAdo apud Táti, I96I, p. 47)

E concluiria:

"Escrevi Cacau com evidentes intenções de propaganda partidária. Conservei-me, porém, rigorosamente honesto, citando apenas fatos que observei." (AMADO apud TÁTI, I96I, p. 47).

A escrita do romance teria tomado impulso quando, em uma viagem de 1932 para o município de Pirangi, no interior da Bahia, o escritor impressionou-se com a vida dos trabalhadores daquela região. 
Suor, o terceiro livro do escritor, publicado em 1934, é um romance ambientado em Salvador e tematiza o suposto proletariado urbano. Segundo Jorge Amado, Suor é também um documento, pois retrata "verdadeiramente" o que ele viveu em meados da década de 20 quando morou numa rua próxima ao Largo do Pelourinho:

Vivi em vários lugares. Durante algum tempo morei numa ruela vizinha ao

Largo do Pelourinho, no coração da velha Babia, um lugar admirável por sua arquitetura e terrivel pelo que significa - o pelourinho era o lugar em que eram castigados publicamente os escravos. A casa em que eu morava era uma construção colonial alta e sombria, onde se amontoava uma multidão de pessoas exóticas. Eu morava bem em cima, numa água-furtada. Hoje transformaram-na num botel, juntando dois sobrados, e até colocaram uma placa indicando que é casa descrita em Suor. É exatamente o que eu mostro neste romance. Suor é verdadeiramente a minha vida no Pelourinho. (Amado apud Raillard, I990, p. 33)

Após Cacau e Suor, Jorge Amado empreendeu a produção de um romance em que um herói, oriundo das massas, se rebela contra o processo histórico que o oprime. Em Jubiabá (1935), o negro Antônio Balduíno, ao adquirir consciência de classe, incita a greve do trabalhador contra o patrão. O escritor revelou que, para a produção do livro, percorreu, durante um mês, a cidade de Salvador, documentando a realidade local:

[...] Cheguei de lá há I5 dias [...]. Eu nasci na Babia e quase todos os anos volto à minha cidade. É admirável! As ruas, os pretos, os saveiros, as feiras [...], as ladeiras [...]. Acho que botei um pouco disso tudo no meu novo romance - Jubiabá - que acaba de aparecer. É a vida pobre dos negros da Babia [...]. Ambientes negros de cais, de casario velho, de macumbas, saveiros, botequins e ainda todo o recôncavo com as suas cidades típicas, as plantaçooes de fumo e as fábricas de charutos. O meu novo romance procura refletir a vida dos pretos da Babia [...] que vivem em meio à miséria maior, sofrendo todos os preconceitos de raça, que ainda dominam o Brasil. (Aмado apud TÁtı, I96I, p. 77) 
Notemos que, influenciado pelo obreirismo do partido - ou seja, a valorização do modo de vida proletário em detrimento do intelectualismo burguês - Amado sentiu a necessidade de sublinhar nos seus comentários o contato próximo com a realidade proletária que "documenta" em seus romances.

A vida política intensa de Jorge Amado o levaria a ser detido em 1936, por causa da Intentona Comunista do ano anterior. Mas os problemas para Amado começaram mais cedo: Cacau já havia experimentado em seu lançamento a mão pesada da censura. Liberado graças à intervenção de amigos, o romance vendeu, em I933, 2000 exemplares em 40 dias. Estava aberto para o escritor o caminho da empatia popular, em paralelo à contínua vigilância do aparelho repressivo. Autor de uma ficção tida como subversiva, Amado foi, então, preso, perseguido e exilado. É na cadeia que assiste à publicação de Mar Morto em 1936. Perdeu o emprego e passou várias privações por falta de dinheiro. Teve seus livros recolhidos das livrarias e sua venda proibida no Brasil. Essa sua prisão foi a primeira de várias outras, que viriam por conta do engajamento.

Em 1937, participou da campanha para eleger José Américo de Almeida a presidente da República. Contudo, ocorreu o golpe de Getúlio, e implantou-se a ditadura do Estado Novo. Novamente, o escritor foi detido. Na prisão, soube da queima pública de seus livros pelo exército, dentre os quais o recém-lançado Capitães da Areia. Depois de proibidos de circular e de serem recolhidos de escolas, bibliotecas e livrarias, quase dois mil exemplares de livros viraram fogueira do fascismo tropical numa praça em Salvador.

Liberto, em I938, passou a trabalhar nos mais diversos jornais de São Paulo e do Rio. Ocupou-se plenamente com a atividade política, combatendo a ditadura, denunciando o fascismo, defendendo a anistia dos que ainda estavam presos. Empenhou-se para reorganizar o Partido Comunista, um tanto esfacelado pela polícia de Vargas. 


\subsection{O Comunismo e o casal Oswald de Andrade e Patrícia GaLṼ̃o}

Em 3o, numa estreita solidariedade com meu estado de
arruinado, tornei-me marxista militante e passei a conhecer
cortiços, vielas, prisóes, lençóis rasgados e fome física. (ANDrade apud Rubim, I990)

A adesão de Oswald de Andrade ao Comunismo foi, sobretudo, incentivada por sua mulher Patrícia Galvão, a Pagu. Quando foi a Buenos Aires, em 1930, para participar de um festival de poesias, Pagu conheceu Luís Carlos Prestes e voltou desse encontro entusiasmada com o Comunismo. A adesão do casal foi rápida e objetiva, conforme ele mesmo expõe em uma entrevista de I9 de setembro de 1954:

- Conte como foi que você aderiu ao comunismo?

- Por culpa de Patrícia Galvão. Ela fizera uma viagem a Buenos Aires, onde realizou um recital de poesia. Voltou com panfletos, livros e uma grande novidade:

- Oswald, tem o comunismo... Conheci um camarada chamado Prestes. Ele é comunista e nós vamos ficar. Você fica?

- "Fico". (Andrade, I990, p. 234)

Oswald e Pagu associaram-se ao Partido Comunista em I93I, no calor da orientação obreirista. A direção do PCB atribuía tarefas difíceis aos novos militantes, a fim de experimentar-lhes a adesão. Uma dessas tarefas foi a de pedir dinheiro ao ex-amigo modernista Paulo Prado.

A crise de 1929 deixou Oswald endividado e estimulou sua militância política. O tempo de festas e viagens havia-se encerrado, dando lugar à incerteza e à clandestinidade. Incorporando o espírito obreirista exigido pelo Partido, Oswald deixou de lado as gravatas e camisas de seda francesas para aderir à indumentária de um operário. Mudou-se com Pagu 
e Nonê para a modesta casa na rua dos Ingleses, n. 56. Levando a cabo a esperança de uma revolução iminente que viesse socializar tudo, Oswald impôs um novo ritmo de vida para o filho: após cinco anos de estudo pago na Suíça, dominando fluentemente francês, alemão e inglês, Nonê foi matriculado pelo pai no Liceu público de Artes e Ofícios para ser transformado em um operário qualificado.

A proletarização de Oswald é vivida ficcionalmente pelo personagem Alfredo Rocha em Parque Industrial, de autoria da mulher Pagu (Galvão, I994, p. 70). Na descrição do personagem, esboça-se um perfil do próprio Oswald. Ele é mostrado como um "burguês hesitante" que se inclina em direção à transformação socialista enquanto lê Marx no conforto do Hotel Esplanada. Após o término do casamento com Eleonora, ele abdica da burguesia:

\footnotetext{
"Abomino esta gente. Estes parasitas... E sou um deles." Sua riqueza o incomoda e tenta ajustar-se à classe operária através do seu recém-descoberto marxismo. Alfredo procura gostar da comida pobre e mal feita. Sente-se feliz. Não acha mais abominável, como antes, o Brasil. Não deseja mais afundar sua neurastenia individualista em nenbum pitoresco. Sem saudades dos hotéis do Cairo nem dos vinhos de França". (GALVão, 1994, p. 88)
}

Seguindo a política do obreirismo, o casal deixou de lado qualquer situação aparentemente capitalista. Oswald, junto de Pagu, celebrava, então, um novo estilo de vida, bem traçado no "Poema à Patrícia":

Sairás pelo meu braço grávida, de bonde

Teremos seis filhos

E três filhas

E nosso bonde social

Terá a compensação dos cinemas

$E$ dos aniversários dos bebês 


\author{
Seremos felizes como os tico-ticos \\ E os motorneiros \\ E teremos o cinismo \\ De ser banais \\ Como os demais
}

Mortais

Locais (ANDRADE, I967, p. 3I-32).

É interessante notar a distância entre as perspectivas de Raquel e de Pagu com relação à política de proletarização dо РСв. Se Raquel condena e critica o obreirismo no seu romance Caminho de Pedras, Pagu o defende com otimismo em Parque Industrial.

Em I931, começava a fase ativista de Pagu e Oswald. Juntos, editaram o jornal O Homem do Povo. O programa do jornal avisava que, embora não estivesse filiado a nenhum partido, apoiaria a esquerda revolucionária em prol da realização das reformas necessárias. Contudo, o jornal teve uma projeção bastante efêmera e tumultuada: de 27 de março a I3 de abril de I93I.

Com o mesmo ânimo e paixão com que defendera o Modernismo, Oswald entregou-se à política. Foi fichado como subversivo e preso várias vezes. Do engajamento político surgiram trabalhos didáticos destinados a operários, textos que também funcionaram como programa do Partido, orientando a discussão interna entre os companheiros. Oswald participou, em 1931, de uma conferência no Sindicato dos Pedreiros, Confeitarias e Anexos, em São Paulo, onde reconstituiu a história dos sindicatos através dos séculos. Essa palestra confirmou o espírito vanguardista do escritor, pois o tema sobre sindicatos era assunto novo: a lei que havia regulamentado a existência das organizações operárias e patronais era do mesmo ano, 1931.

Em 1932, Pagu separou-se de Oswald. Foi morar no Rio de Janeiro numa vila operária e trabalhar num cinema da Cinelândia, como indica- 
dora de lugares. Esta mudança fazia parte do projeto obreirista do $\mathrm{Co}^{-}$ munismo, forçando os intelectuais a experimentarem também a vida e o trabalho como operários.

A atividade literária, em prosa, de Patrícia Galvão iniciou-se nesse mesmo ano de 1932, quando começou a escrever Parque Industrial. Pagu adotou o pseudônimo de Mara Lobo por exigência do Partido Comunista. Em 1931, instalou-se no bairro operário do Brás em São Paulo e acompanhou de perto o cotidiano dos trabalhadores, envolvido por nebulosa exploração. Resignou-se a abandonar a vida burguesa e viu de perto muita miséria nos subúrbios e nas fábricas. Misturou-se com pessoas discriminadas pela falta de instrução. Ouviu gritos, pragas, palavrões, e documentou tudo em Parque Industrial.

A produção literária de Oswald também foi fecunda na década de 30. Em I933, ele lançou Serafim Ponte Grande, obra que marca a opção do escritor pela literatura política:

"Publico-o [...] no seu texto integral, terminado em 1928. Necrológio da burguesia. Epitáfio do que eu fui". (ANDRADE, 1992, p. 39)

Renega então os seus livros anteriores. Ousou sugerir que Serafim Ponte Grande era o novo manifesto da Revolução Proletária.

Publicado Parque Industrial em I933, Pagu deixou o país e empreendeu uma viagem pelo mundo percorrendo os EUA, Japão, China, URss, Alemanha e França. Retornou ao Brasil em 1935 e defrontou-se com um país mergulhado em crises políticas: o Congresso Nacional fechado, sindicato e associações sob intervenção, prisões políticas, tortura e imprensa sob censura prévia - essas foram algumas das armas do governo para conter e silenciar a oposição depois da Intentona Comunista. Pagu foi presa novamente, dessa vez por cinco anos (1935-1940). 
Oswald foi de grande apoio para os colegas presos, inclusive Pagu. Apesar das sátiras políticas registradas no jornal A Platéia, desviou-se da ortodoxia política. Com isso, evitou sua prisão.

\section{DesfiLIAÇÃo}

Expulsara finalmente de minha vida o Partido Comunista. De degrau em degrau desci a escada das degradações, porque o Partido precisava de quem não tivesse um escrúpulo, de quem não tivesse personalidade, de quem não discutisse. De quem ACEITASSE.

(Galvão apud Campos, 1982)

A ditadura do Estado Novo, pela sua violência contra о РСв e contra os indivíduos que dele se aproximavam, contribuiu para a cisão entre o Partido e a intelectualidade. Também a linha política partidária pautada na rígida ditadura stalinista teve influência no afastamento dos intelectuais.

A fase de proletarização afastou muitos deles, que viram, nessa medida, uma total falta de critérios. O Partido designava tarefas abusivas, totalmente distanciadas de habilitações pessoais e profissionais; negava o direito de voto e nomeava para a sua direção somente lideranças oriundas do proletariado. Devido, sobretudo, à política arbitrária do $\mathrm{PCB}$, a presença dos intelectuais no Partido foi encarada, então, como sectarismo. Acreditava-se que o intelectual que se filiasse ao Partido deveria abdicar, antes de tudo, à sua condição de intelectual. $\mathrm{Na}$ verdade, o que se pretendia era restringir a atuação do intelectual, condená-lo a ser um prático, um simples cumpridor de tarefas. Não se compreendia, então, que o intelectual poderia ser um combatente pela causa do Socialismo, precisamente desempenhando seu papel como intelectual comunista. 
Em 1932, Raquel de Queiroz abandonou o Partido Comunista devido à política de proletarização e à tentativa de censura de seu trabalho literário. Após cinco anos de prisão (I935-1940), em plena ditadura do Estado Novo, Pagu, ao sair do presídio político, rompeu definitivamente сот о Рсв por causa das tarefas abusivas a que fora submetida. Oswald iria romper com o Partido em I945 e Jorge Amado em 1955.

\section{Considerações Finais}

Este trabalho se propôs a contar a (possível) história das relações entre os literatos brasileiros e o Comunismo, dentro do lapso selecionado: a década de I930. Ao sublinhar a filiação dos escritores ao Partido Comunista do Brasil (РСв), sua adesão ao obreirismo e à literatura proletária, comentando, em particular, sobre aqueles filiados, de fato, ao partido - Raquel de Queiroz, Jorge Amado e o casal Oswald de Andrade e Pagu - pretendeu registrar trajetórias representativas do engajamento do intelectual brasileiro no período referido.

Note-se que o trabalho não tem, em absoluto, a pretensão de ser a única versão daquela história. Tanto são possíveis outros recortes, quanto, dentro do mesmo recorte, outras possibilidades de contar se apresentam.

\section{Bibliografia}

Amado, Jorge. Homens e coisas do Partido Comunista. Rio de Janeiro: Horizonte, 1946. . Navegação de Cabotagem. Rio de Janeiro: Record, I993.

Andrade, Oswald. Os dentes do dragão. São Paulo: Globo, I990. . Serafim Ponte Grande. São Paulo: Globo, 1992.

. Trechos escolbidos. Rio de Janeiro: Agir, 1967.

Campos, Augusto de. Pagu: Vida e Obra. São Paulo: Brasiliense, 1982. 
Galvão, Patrícia. Parque Industrial. São Paulo: edufscar, 1994.

Konder, Leandro. Intelectuais Brasileiros e Marxismo. Belo Horizonte:

Oficina de Livros, I991.

Queiroz, Raquel de. Caminho de Pedras. Rio de Janeiro: José Olympio, 1976.

; Queiroz, Maria Luíza de. Tantos Anos. São Paulo: Siciliano, 1998.

Raillard, Alice. Conversando com Jorge Amado. Trad. Annie Dymetman. Rio de Janeiro: Record, 1990.

Rubim, Antônio Albino Canelas. Marxismo, Cultura e Intelectuais no Brasil. Salvador: Centro Editorial e Didático da UfBA, 1995.

TÁtı, Miécio. Jorge Amado: vida e obra. Belo Horizonte: Itatiaia, I96I.

Aвstract: This work displays the relationships between brazilian intellectuals and the communism in the 1930s, showing their affiliation with the Communist Party and their commitment to proletarian literature.

KeYwORDS: Literature; Communism; Intellectuals 